\title{
No Evidence of the Monomer in the Extraction of Copper(II) with Carboxylic Acids Having Bulky Substituent at $\alpha$-Position
}

\author{
Yoshio MoriYa*, Nobuaki Ogawa**, Mikio Sugai* and Yozo OHShima* \\ *Faculty of Mining, Akita University, Tegata Gakuencho, Akita 010, Japan \\ **Faculty of Education, Akita University, Tegata Gakuencho, Akita 010, Japan
}

\begin{abstract}
The extraction behavior of copper(II) with three carboxylic acids having a bulky substituent at the $\alpha$-position was investigated in order to clarify the steric effect on the dimerization of copper(II) carboxylate extracted in benzene. Pivalate and 2-ethylbutyrate were found to be extracted only as a dimeric species $\mathrm{Cu}_{2} \mathrm{~L}_{4}(\mathrm{HL})_{2}$ through the slope analyses, taking into account the formation constant of $(1: 1)$ copper carboxylate complex in the aqueous phase. A new computing method based on fixing the species to the composition, $\mathrm{Cu}_{2} \mathrm{~L}_{4}(\mathrm{HL})_{2}$, was proposed to estimate both the dimerization constant of carboxylic acid $\left(K_{2, \mathrm{HL}}\right)$ and the extraction constant of the dimeric copper species $\left(K_{\mathrm{ex}(22)}\right)$ for the case of carboxylic acid of higher carbon number in nonpolar solvents, and the extracted diphenylacetate was also found to be only a dimer as is usual. Consequently, under our experimental conditions, there was no evidence for the coextraction of monomeric copper(II) species caused by the steric hindrance as reported in other papers. Moreover, a linear relationship between $\log K_{\mathrm{ex}(22)}$ and $\log K_{\mathrm{a}}$ was maintained by adding the three bulky substituent carboxylic acids.
\end{abstract}

Keywords Extraction, copper(II), carboxylic acid, bulky substituent, steric hindrance, monomer

The extraction behavior of metals with carboxylic acids depends first on the bonding character of the metal ions to the oxygen atoms of the functional carboxyl group. ${ }^{1}$ On the other hand, the influence of the carboxylic acid residue on metal extraction behavior can be sited as a secondary factor in the sense that it affects the extraction equilibria of the copper(II) carboxylates. This comes about the central copper(II) ion can occasionally be extracted as a monomeric species along with the well-known dimeric species, $\mathrm{Cu}_{2} \mathrm{~L}_{4}(\mathrm{HL})_{2}$, with certain carboxylic acids in nonpolar solvents. ${ }^{2}$ A monomeric copper(II) carboxylate such as $\mathrm{CuL}_{2}(\mathrm{HL})_{2}$ would be extracted in preference to the dimeric one. The copper(II) decanoate system ${ }^{3}$ has been analyzed in the low concentration region present in the organic phase $\left(C_{\mathrm{Cu}, \mathrm{o}}<10^{-5} \mathrm{M}\right)$. The coextraction of a monomer accompanied by a dimer in the region of $C_{\mathrm{Cu}, \mathrm{O}}$ above $10^{-4} \mathrm{M}$ was first reported by using pivalic acid in toluene. ${ }^{4}$ Similar behaviors were found in the systems of cyclohexanecarboxylic acid ${ }^{5}$, pivalic acid $^{6}$, phenylacetic acid ${ }^{7}$, benzoic acid ${ }^{8}$ and recently in that of 1-naphthalenecarboxylic acid $^{9}$ in benzene. Furthermore, a single monomeric species also has been reported for the system of 2-bromododecanoic acid ${ }^{10}$ in hexane. As for the system of 1-adamantanecarboxylic acid in benzene, however, we could not obtain any evidence for the coextraction of the monomeric copper species in the region of $C_{\mathrm{Cu}, 0}$ above $30 \mu \mathrm{M}$ as has already been described in a previous report. ${ }^{11}$ The above result requires further experiment, in particular on the steric hindrance that is caused by some substituents contained in the carboxylic acid.

In this paper, we describe the extraction behavior of copper(II) with three carboxylic acids (pivalic, 2ethylbutyric and diphenylacetic acids) possessing bulky substituents at the $\alpha$-position, in order to clarify the steric effect on the dimerization of copper(II) carboxylate extracted in benzene. We have also proposed a new method for the estimation of the two unknown constants in a nonpolar solvent system, i.e., dimerization constant of carboxylic acid $\left(K_{2, \mathrm{HL}}\right)$ and extraction constant of dimeric copper(II) species $\left(K_{\text {ex (22) }}\right)$, since we often face the need to use such constants when an acid of higher carbon number has to be examined.

\section{Experimental}

\section{Reagents}

Commercially obtained carboxylic acids (purities: over $99 \%$, Tokyo Chemical Industry Co. Ltd.); pivalic, 2ethylbutyric and diphenylacetic acids were dissolved in benzene saturated with deionized and distilled water. Copper(II) nitrate (purity 99.9\%, Wako Pure Chem. Co. Ltd.) was employed to study the copper(II) extraction equilibria at a constant ionic strength $(I=0.1 \mathrm{M}$, $\left.(\mathrm{Na}, \mathrm{H}) \mathrm{NO}_{3}\right)$ as in our previous work. ${ }^{1}$ However, perchloric acid and sodium perchlorate (Wako Pure Chem. Co. Ltd.) were also used for the fundamental studies of equilibria on both the dissociation and the partition of carboxylic acids or of the photometric determination of the aqueous formation constant of copper(II) car- 
boxylate complex under the constant ionic strength $\left(I=0.1 \mathrm{M}\right.$. $\left.(\mathrm{Na}, \mathrm{H}) \mathrm{ClO}_{4}\right)$. For the latter, copper(II) perchlorate was prepared by the reaction of metallic copper (E. Merck, purity $99.99 \%$ ) with $60 \%$ perchloric acid. All other chemicals were of analytical reagent grade.

\section{Apparatus and procedure}

The extractions of copper(li) carboxylates were carried out by mixing the same volume $(10 \mathrm{ml})$ of aqueous and organic solutions under the following conditions: an initial copper concentration of $5 \mathrm{mM}$ in aqueous phase and a total concentration in the region of $0.15-0.6 \mathrm{M}$ of pivalic acid and 2-ethylbutyric acid, in benzene, and an initial copper(II) concentration of $2 \mathrm{mM}$ and a total concentration in the region of $0.08-0.18 \mathrm{M}$ of diphenylacetic acid in benzene. The concentrations of copper in both phases were determined complexometrically using EDTA $(10 \mathrm{mM}$ or $1 \mathrm{mM})$ with 4-(2-thiazolylazo)resorcinol (TAR) as an indicator. Apparatus and the other procedures were the same as employed previously. ${ }^{11}$

\section{Results and Discussion}

\section{Several equilibrium constants}

For the analyses of the extraction equilibria of metal carboxylates, we must obtain information on the partition of carboxylic acid itself, especially, of the lower fatty acids, since such information could not be found in the literature. For the pivalic acid or the 2-ethylbutyric acid systems, information is also needed about the formation constant of copper(II) complex in the aqueous phase, and also the dissociation constant of the carboxylic acid will be needed to be determined. These values relate to the side reaction coefficients in the aqueous phase and are used to analyze the extraction equilibria more precisely.

\section{Dissociation constants}

We determined the dissociation constants $K_{\mathrm{a}}\left(=\left[\mathrm{H}^{+}\right]\right.$. $\left.\left(\mathrm{L}^{-}\right] /[\mathrm{HL}]\right)$ of pivalic acid and of 2-ethylbutyric acid in the aqueous phase potentiometrically at $25^{\circ} \mathrm{C}$ to be $10^{-4.86}$ and $10^{-4.54}$, respectively, after the correction of the activity coefficient of $\mathrm{H}^{+}$ion $\left(y_{\mathrm{H}^{+}}\right)$at $I=0.1$. The value of $K_{\mathrm{a}}$ for the diphenylacetic acid was photometrically determined using the equation:

$$
C_{\mathrm{HL}}^{0} /\left(A-A_{\mathrm{HL}}^{0}\right)=1 /\left(\varepsilon_{\mathrm{L}^{-}}-\varepsilon_{\mathrm{HL}}\right)+\left[\mathrm{H}^{+}\right] /\left\{\left(\varepsilon_{\mathrm{L}^{-}}-\varepsilon_{\mathrm{HL}}\right) K_{\mathrm{a}}\right\},
$$

where $A_{\mathrm{HL}}^{0}$ and $A$ denote the absorbances for the solution of undissociated carboxylic acid (HL) and for the equilibrated solution ( $\mathrm{HL}$ and $\mathrm{L}^{-}$) at the $\left[\mathrm{H}^{+}\right]$under the initial concentration $C_{\mathrm{HL}}^{0}$, while $\varepsilon_{\mathrm{HL}}$ and $\varepsilon_{\mathrm{L}^{-}}$denote the molar absorption coefficients for carboxylic acid and for carboxylate ion, respectively. The solutions mentioned above were easily prepared by adding a trace amount (within a small droplet) of the concentrated solution of
$\mathrm{HClO}_{4}$ or of $\mathrm{NaOH}$ to a $30-50 \mathrm{ml}$ volume of the initial aqueous solution. A combination glass electrode was then inserted for $\mathrm{pH}$ measurement to maintain the final concentration of carboxylic acid as close to the initial concentration of $C_{\mathrm{HL}}^{0}$, i.e., within our experimental error. The mean value for $K_{\mathrm{a}}$ was $10^{-3.64}$ for the diphenylacetic acid under the conditions: $C_{\mathrm{HL}}^{0} ; 0.1 \mathrm{mM}$, range of wavelength; $220-228 \mathrm{~nm}$ and $\mathrm{pH}$ range; $1.49-4.25$. In the same manner, we also obtained $K_{\mathrm{a}}=10^{-3.92}$ for 1-adamantanecarboxylic acid, with which we had previously dealt ${ }^{11}$, under the conditions: $C_{\mathrm{HL}}^{0}, 0.4 \mathrm{mM}$; wavelength, $200-210 \mathrm{~nm}$ and $\mathrm{pH}, 3.0-5.5$.

2. Partitions of pivalic and 2-ethylbutyric acid

The partition ratio $D$ of a carboxylic acid between the organic and the aqueous phase can be represented as:

$$
\begin{aligned}
D & =C_{\mathrm{HL}, \mathrm{o}} / C_{\mathrm{HL}, \mathrm{w}} \\
& =\left(K_{\mathrm{D}, \mathrm{HL}}+2 K_{2, \mathrm{HL}} K_{\mathrm{D}, \mathrm{HL}}^{2}[\mathrm{HL}]\right)\left(1+K_{\mathrm{a}} /\left[\mathrm{H}^{+}\right]\right)^{-1},
\end{aligned}
$$

where $K_{\mathrm{D}, \mathrm{HL}}$ and $K_{2, \mathrm{HL}}$ denote the partition constant between the organic and the aqueous phases and the dimerization constant in the organic phase, respectively. Since the aqueous dissociation of carboxylic acid can be ignored under such conditions $\mathrm{pH}<\left(\mathrm{p} K_{\mathrm{a}}-2\right)$, the factor $\left(1+K_{\mathrm{a}} /\left[\mathrm{H}^{+}\right]\right)^{-1}$ can be taken as unity. Then we can obtain the values of $K_{\mathrm{D}, \mathrm{HL}}$ and $K_{2, \mathrm{HL}}$ from the intercept $\left(K_{\mathrm{D}, \mathrm{HL}}\right)$ and the slope $\left(2 K_{2, \mathrm{HL}} K_{\mathrm{D} . \mathrm{HL}}{ }^{2}\right)$ of the straight line from the plot of $D$ against [HL]. The partition was carried out between benzene and $1 \mathrm{mM}$ perchloric acid containing $99 \mathrm{mM}$ sodium perchlorate. The concentrations of carboxylic acid in both phases after equilibration were determined titrimetrically with the standard sodium hydroxide as described in the literature. ${ }^{12}$ From Fig. 1, the values of $\log K_{\mathrm{D}, \mathrm{HL}}$ and $\log K_{2, \mathrm{HL}}$ were calculated to be $-0.03,2.32$ for (a) pivalic acid and to be $0.04,2.83$ for (b) 2-ethylbutyric acid, respectively. The values of the former were comparable to the known values ${ }^{6}$ of 0.02 , 2.16 .

3. Formation of copper(II) carboxylate in aqueous solution

Considering that the [HL] calculated by Eq. (2) is relatively low for the system of pivalic acid and 2ethylbutyric acid systems and that the stability constants $k_{\text {CuL }}$ for the $(1: 1)$ copper(II) carboxylates ${ }^{13}$ are around $10^{2}$ (that belong to a so-called weak complex), it is feasible for us under our experimental conditions to take into account of only the (1:1) copper(II) carboxylate formation equilibrium:

$$
\begin{aligned}
& \mathrm{Cu}^{2+}+\mathrm{HL} \rightleftarrows \mathrm{CuL}^{+}+\mathrm{H}^{+} \\
& K_{1}=\left[\mathrm{CuL}^{+}\right]\left[\mathrm{H}^{+}\right]\left[\mathrm{Cu}^{2+}\right]^{-1}\left[\mathrm{HL}^{-1}\right.
\end{aligned}
$$

which relates to the side reaction coefficient in the aqueous phase. The formation constant $K_{1}$ for copper(II) pivalate or 2-ethylbutyrate in aqueous solution was determined by means of spectrophotometry. When the molar concentration of $\mathrm{CuL}^{+}$after equilibration at the $\left[\mathrm{H}^{+}\right]$is represented by $X$ under the condition 


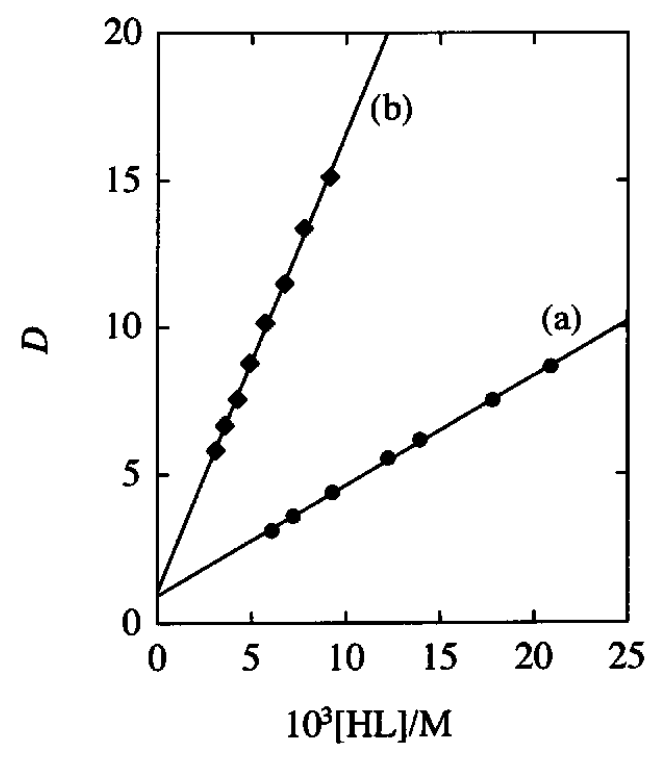

Fig. 1 Determinations of the distribution constant between benzene and aqueous phases and of the dimerization constant in the organic phase for (a) pivalic acid and (b) 2ethylbutyric acid.

where the molar concentration $\left(C^{0}\right)$ of copper(II) is equal to that of carboxylic acid, the formation constant $K_{1}$ can be written as Eq. (4):

$$
K_{1}=X\left[\mathrm{H}^{+}\right] /\left(C^{0}-X\right)^{2} .
$$

The absorbance of the solution is represented as:

(a)

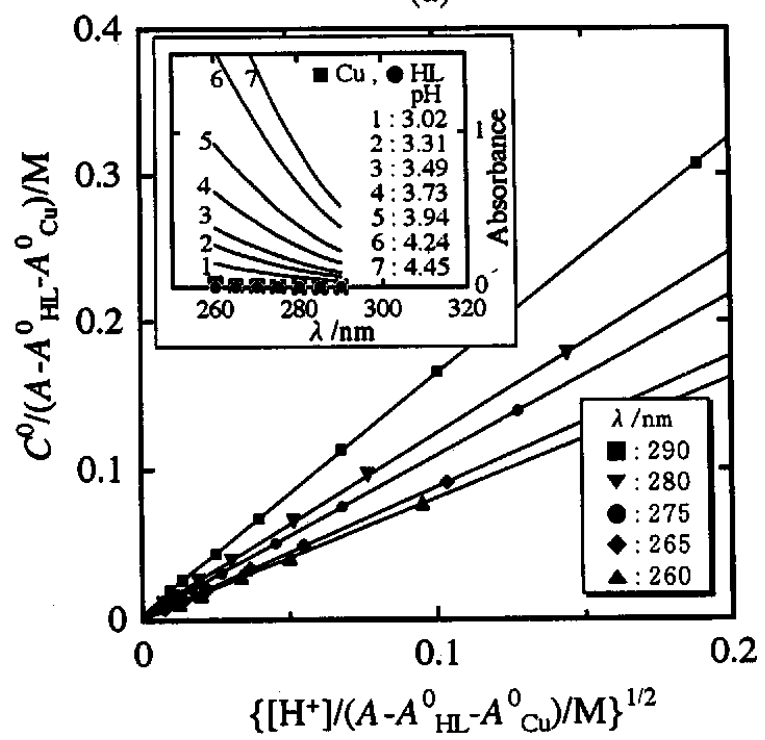

$$
\begin{aligned}
A & =X \varepsilon_{\mathrm{CuL}}+\left(C^{0}-X\right) \varepsilon_{\mathrm{HL}}+\left(C^{0}-X\right) \varepsilon_{\mathrm{Cu}} \\
& =X\left(\varepsilon_{\mathrm{CuL}}-\varepsilon_{\mathrm{HL}}-\varepsilon_{\mathrm{Cu}}\right)+A_{\mathrm{HL}}^{0}+A_{\mathrm{Cu}}^{0}
\end{aligned}
$$

where $\varepsilon_{\mathrm{Cu}}$ and $\varepsilon_{\mathrm{CuL}}$ denote the molar absorption coefficients for hydrated $\mathrm{Cu}^{2+}$ ion and for (1:1) copper(II) carboxylate complex, respectively, and $A_{\mathrm{Cu}}^{0}$ is the absorbance for aqueous copper(II) solution at the initial concentration $C^{\circ}$. Therefore, we can derive the final Eq. (6) by combining Eq. (4) with $X=\left(A-A_{\mathrm{HL}}^{0}-A_{\mathrm{Cu}}^{0}\right) /$ $\left(\varepsilon_{\mathrm{CuL}}-\varepsilon_{\mathrm{HL}}-\varepsilon_{\mathrm{Cu}}\right)$ from Eq. (5):

$$
\begin{aligned}
& C^{0} /\left(A-A_{\mathrm{HL}}^{0}-A_{\mathrm{Cu}}^{0}\right)=1 /\left(\varepsilon_{\mathrm{CuL}}-\varepsilon_{\mathrm{HL}}-\varepsilon_{\mathrm{Cu}}\right) \\
& \quad+\left[1 /\left\{\left(\varepsilon_{\mathrm{CuL}}-\varepsilon_{\mathrm{HL}}-\varepsilon_{\mathrm{Cu}}\right) K_{\mathrm{l}}\right\}\right]^{1 / 2}\left\{\left[\mathrm{H}^{+}\right] /\left(A-A_{\mathrm{HL}}^{0}-A_{\mathrm{Cu}}^{0}\right)\right\}^{1 / 2} .
\end{aligned}
$$

The linear plots of $C^{0} /\left(A-A_{\mathrm{HL}}^{0}-A_{\mathrm{Cu}}^{0}\right) v s .\left\{\left[\mathrm{H}^{+}\right] /\left(A-A_{\mathrm{HL}}^{0}\right.\right.$ $\left.\left.-A_{\mathrm{Cu}}^{0}\right)\right\}^{1 / 2}$ obtained at several values of $\mathrm{pH}$ and wavelength for an initial concentration of $C^{0}=9.83 \times 10^{-3} \mathrm{M}$ are shown in Fig. 2(a) for copper(II) pivalate and Fig. 2(b) for copper(II) 2-ethylbutyrate. Since the value of $K_{1}$ is obtained from the intercept, $1 /\left(\varepsilon_{\mathrm{CuL}}-\varepsilon_{\mathrm{HL}}-\varepsilon_{\mathrm{Cu}}\right)$ and the slope $\left\{1 /\left(\varepsilon_{\mathrm{CuL}}-\varepsilon_{\mathrm{HL}}-\varepsilon_{\mathrm{Cu}}\right) K_{1}\right\}^{1 / 2}$, the stability constant, $k_{\mathrm{CuL}}\left(=\left[\mathrm{CuL}^{+}\right]\left[\mathrm{Cu}^{2+}\right]^{-1}\left[\mathrm{~L}^{-}\right]^{-1}\right)$ can be calculated as:

$$
k_{\mathrm{CuL}}=K_{1} / K_{\mathrm{a}}
$$

The mean value of $\log k_{\text {cuL }}$ was calculated to be 2.10 for copper(II) pivalate and 1.92 for copper(II) 2ethylbutyrate.

\section{Extraction of copper(II) carboxylates}

When the extracted species is generally expressed as

Fig. 2 Determination of the formation constant for $(1: 1)$ copper(II) carboxylate complex in the aqueous solution at the initial concentrations $C^{0}=C_{\mathrm{HL}}^{0}=C_{\mathrm{Cu}}^{0}=9.83 \times 10^{-3} \mathrm{M}$. Ligand: (a) pivalic acid, (b) 2-ethylbutyric acid. 

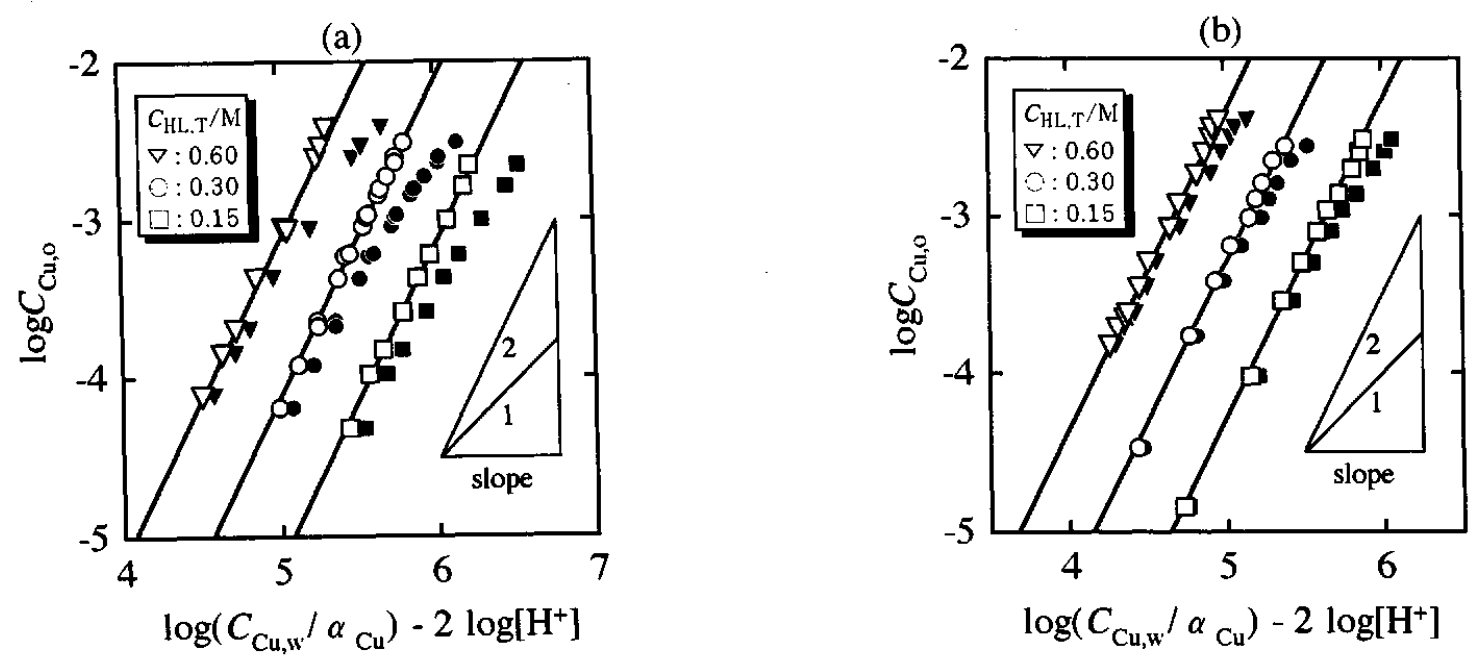

Fig. 3 Determination of the degree of oligomerization for (a) copper(II) pivalate or (b) copper(II) 2-ethylbutyrate in benzene. Open symbols show the experimental data. Solid lines are calculated from the results obtained in this work. Closed marks are calculated as $\alpha_{\mathrm{Cu}}=1$.

$\mathrm{Cu}_{j} \mathrm{~L}_{2 j}(\mathrm{HL})_{m}$, the extraction equilibrium and the extraction constant can be written as follows:

$$
\begin{gathered}
j \mathrm{Cu}^{2+}+0.5(2 j+m)(\mathrm{HL})_{2,0} \rightleftarrows\left(\mathrm{Cu}_{j} \mathrm{~L}_{2 j}(\mathrm{HL})_{m}\right)+2 j \mathrm{H}^{+} \\
K_{\text {ex }(j m)}=\left[\mathrm{Cu}_{j} \mathrm{~L}_{2 j}(\mathrm{HL})_{m}\right]_{0}\left[\mathrm{H}^{+}\right]^{2 j}\left[\mathrm{Cu}^{2+}\right]^{-j}\left[(\mathrm{HL})_{2}\right]_{0}^{-0.5(2 j+m)},
\end{gathered}
$$

where $(\mathrm{HL})_{2}$ represents the carboxylic acid dimer in a nonpolar solvent and the subscript o refers to the organic phase. Then, the total concentration of copper(II) in the organic phase can be expressed as follows:

$$
\begin{aligned}
C_{\mathrm{Cu}, 0} & =\sum_{j} \sum_{m} j\left[\mathrm{Cu}_{j} \mathrm{~L}_{2 j}(\mathrm{HL})_{m}\right]_{\mathrm{o}} \\
& =\sum_{j m} \sum_{m}\left(j K_{\mathrm{ex}(j m[}\left[(\mathrm{HL})_{2}\right]_{0}^{0.5(2 j+m)}\left[\mathrm{Cu}^{2+}\right]^{j}\left[\mathrm{H}^{+}\right]^{-2 j}\right) .
\end{aligned}
$$

When only one species of $\mathrm{Cu}_{j} \mathrm{~L}_{2 j}(\mathrm{HL})_{m}$ exists in the organic phase, the following equation is obtained:

$$
\begin{aligned}
\log C_{\mathrm{Cu}, \mathrm{o}}= & j\left(\log \left[\mathrm{Cu}^{2+}\right]-2 \log \left[\mathrm{H}^{+}\right]\right) \\
& +0.5(2 j+m) \log \left[(\mathrm{HL})_{2}\right]_{\mathrm{o}}+\log \left(j K_{\mathrm{ex}(j m)}\right) .
\end{aligned}
$$

The concentration of copper(II) in the aqueous phase, $C_{\mathrm{Cu}, \mathrm{w}}$ can be used for [ $\left.\mathrm{Cu}^{2+}\right]$ in Eq. (10), when we ignore the concentration of the carboxylic acid distributed into the aqueous phase as in the case of diphenylacetic acid.

In the case of pivalic acid or 2-ethylbutyric acid, however, it is necessary to take into account at least the following side reaction coefficient:

$$
\alpha_{\mathrm{Cu}}=1+k_{\mathrm{CuL}}\left[\mathrm{L}^{-}\right]
$$

which is based on the formation of $1: 1$ copper(II) carboxylate complex in the aqueous phase because of their lower $K_{\mathrm{D}, \mathrm{HL}}$ values. Therefore, Eq. (10) must be rewritten by replacing $\left[\mathrm{Cu}^{2+}\right]$ by $C_{\mathrm{Cu}, \mathrm{w}} / \alpha_{\mathrm{Cu}}$ to yield the following equation:

$$
\begin{aligned}
\log C_{\mathrm{Cu}, \mathrm{o}}= & j\left\{\log \left(C_{\mathrm{Cu}, \mathrm{w}} / \alpha_{\mathrm{Cu}}\right)-2 \log \left[\mathrm{H}^{+}\right]\right\} \\
& +0.5(2 j+m) \log \left[(\mathrm{HL})_{2}\right]_{\mathrm{o}}+\log \left(j K_{\mathrm{ex}(j m)}\right) .
\end{aligned}
$$

The values of both $\left[(\mathrm{HL})_{2}\right]_{\mathrm{o}}$ and $\left[\mathrm{L}^{-}\right]$for the above two acids can be calculated from the next Eq. (13) under the total acid concentration $C_{\mathrm{HL}, \mathrm{T}}$ in a large excess of copper:

$$
\begin{gathered}
2 K_{\mathrm{D}, \mathrm{HL}}{ }^{2} K_{2, \mathrm{HL}}[\mathrm{HL}]^{2}+\left(K_{\mathrm{D}, \mathrm{HL}}+1+\right. \\
\left.K_{\mathrm{a}} /\left[\mathrm{H}^{+}\right]\right)[\mathrm{HL}]-C_{\mathrm{HL}, \mathrm{T}}=0 .
\end{gathered}
$$

1. Extractions of copper(II) pivalate and 2-ethylbutyrate The extraction of copper(II) with pivalic acid or with 2ethylbutyric acid was started at an initial copper concentration $(5 \mathrm{mM})$. The plots of $\log C_{\mathrm{Cu}, \mathrm{o}} v s . \log \left(C_{\mathrm{Cu}, \mathrm{w}} /\right.$ $\left.\alpha_{\mathrm{Cu}}\right)-2 \log \left[\mathrm{H}^{+}\right]$for $C_{\mathrm{HL}, \mathrm{T}}=0.60,0.30$ and $0.15 \mathrm{M}$ of pivalic acid and of 2-ethylbutyric acid are shown in Figs. 3(a) and 3(b), respectively. Linear relationships with a slope $(j)$ of 2.0 are observed for each $C_{\mathrm{HL}, \mathrm{T}}$, and the result shows that the extracted species may be only a dimer for both pivalic and 2-ethylbutyric acid systems. It should be noted in the figure that an unreasonable nonlinear relation is produced (closed symbols are plotted if $\alpha_{\mathrm{Cu}}=1$ in Figs. 3(a) and 3(b)) unless one takes into account of the formation of copper carboxylate in aqueous phase.

The plots of $\log C_{\mathrm{Cu}, \mathrm{o}}-2\left\{\log \left(C_{\mathrm{Cu}, \mathrm{w}} / \alpha_{\mathrm{Cu}}\right)-2 \log \left[\mathrm{H}^{+}\right]\right\}$vs. $\log \left[(\mathrm{HL})_{2}\right]_{\mathrm{o}}$ gave a linear relation with a slope of 3.0 that means the integer $m=2$ for (a) pivalic acid or (b) 2- 


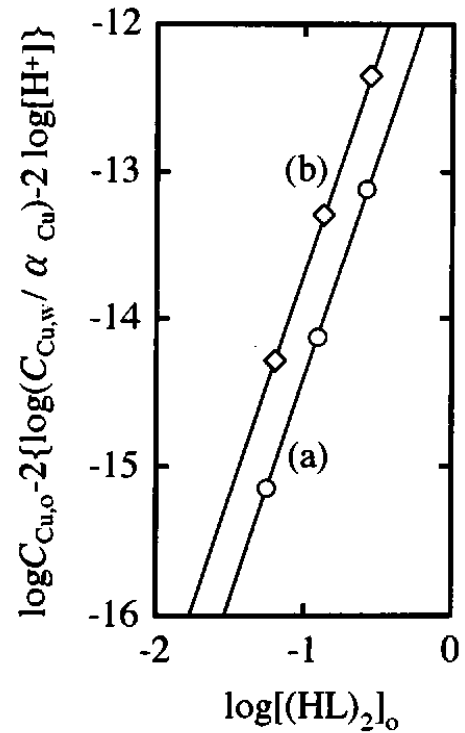

Fig. 4 Determination of the number of (a) pivalic acid molecules and of (b) 2-ethylbutyric acid molecules involved in their dimeric copper(II) species. The slope is 3.0 for the solid line.

ethylbutyric acid, as shown in Fig. 4. Therefore, the likely composition must be $\mathrm{Cu}_{2} \mathrm{~L}_{4}(\mathrm{HL})_{2}$ for both extracted species.

If the $\mathrm{Cu}_{2} \mathrm{~L}_{4}(\mathrm{HL})_{2}$ composition is the only extracted species, then all of the data in Figs. 3(a) or 3(b) should fit to the equation:

$$
\begin{aligned}
& \log C_{\mathrm{Cu}, 0}-3 \log \left[(\mathrm{HL})_{2}\right]_{\mathrm{o}} \\
& \quad=2\left\{\log \left(C_{\mathrm{Cu}, \mathrm{w}} / \alpha_{\mathrm{Cu}}\right)-2 \log \left[\mathrm{H}^{+}\right]\right\}+\log \left(2 K_{\operatorname{ex}(22)}\right) .
\end{aligned}
$$

The plots of $\log C_{\mathrm{Cu}, \mathrm{o}}-3 \log \left[(\mathrm{HL})_{2}\right]_{\mathrm{o}}$ vs. $2\left\{\log \left(C_{\mathrm{Cu}, \mathrm{w}} /\right.\right.$ $\left.\left.\alpha_{\mathrm{Cu}}\right)-2 \log \left[\mathrm{H}^{+}\right]\right\}$are shown in Fig. 5 for every combination of $C_{\mathrm{HL}, \mathrm{T}}$ of (a) pivalic acid and of (b) 2-ethylbutyric acid. The two plots both fit well with their respective straight lines with a slope of 1.0 (correlation coefficient, $r=1.000$ by using the least squares method). This result shows that the extracted species is $\mathrm{Cu}_{2} \mathrm{~L}_{4}(\mathrm{HL})_{2}$ and also that there is no evidence for the monomeric species with our experimental conditions. The intercept at $2\left\{\log \left(C_{\mathrm{Cu}, \mathrm{w}} / \alpha_{\mathrm{Cu}}\right)-2 \log \left[\mathrm{H}^{+}\right]\right\}=0$ in Fig. 5 yields the value of $\log \left(2 K_{\text {ex(22) }}\right)$. Thus, we obtained $\log K_{\operatorname{ex}(22)}=-11.70$ for dimeric copper(II) pivalate and -10.99 for dimeric copper(II) 2-ethylbutyrate. The former is slightly higher than that reported as $-11.81 .^{6}$

2. Extraction of copper(II) diphenylacetate

The extractions of copper(II) with diphenylacetic acid were carried out under the following experimental conditions: a $2 \mathrm{mM}$ aqueous solution of the initial copper and a total acid concentration, $C_{\mathrm{HL}, \mathrm{T}} ; 0.18,0.12$ and $0.08 \mathrm{M}$, because of the lower solubility of the acid in benzene. Considering the lower solubility of diphenylacetic acid in water $(c a .0 .1 \mathrm{mM})$, the assumption $\alpha_{\mathrm{Cu}}=1$ will be acceptable in our experimental conditions.

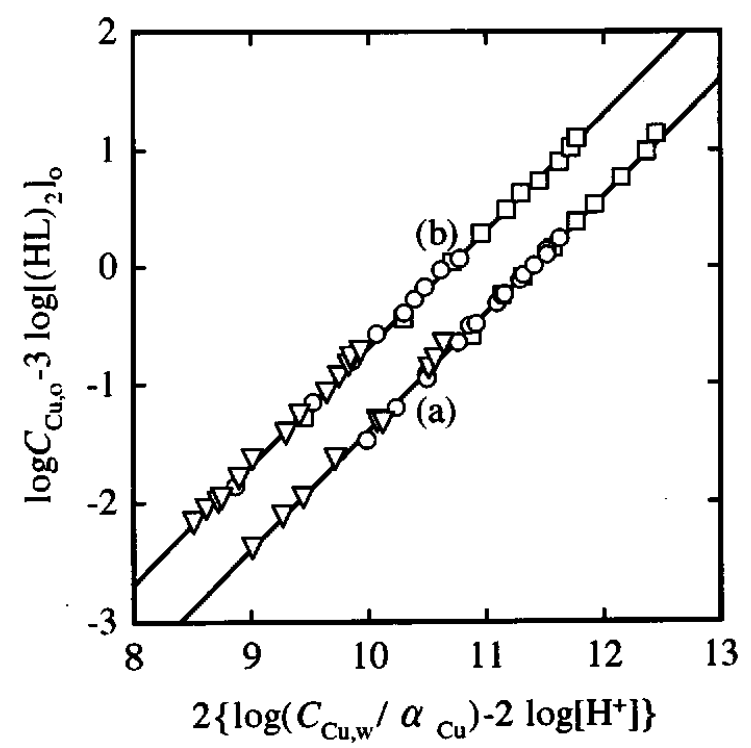

Fig. 5 Confirmations of the composition $\mathrm{Cu}_{2} \mathrm{~L}_{4}(\mathrm{HL})_{2}$ and the extraction constant for (a) pivalate and for (b) 2ethylbutyrate. See the captions in Fig. 3.

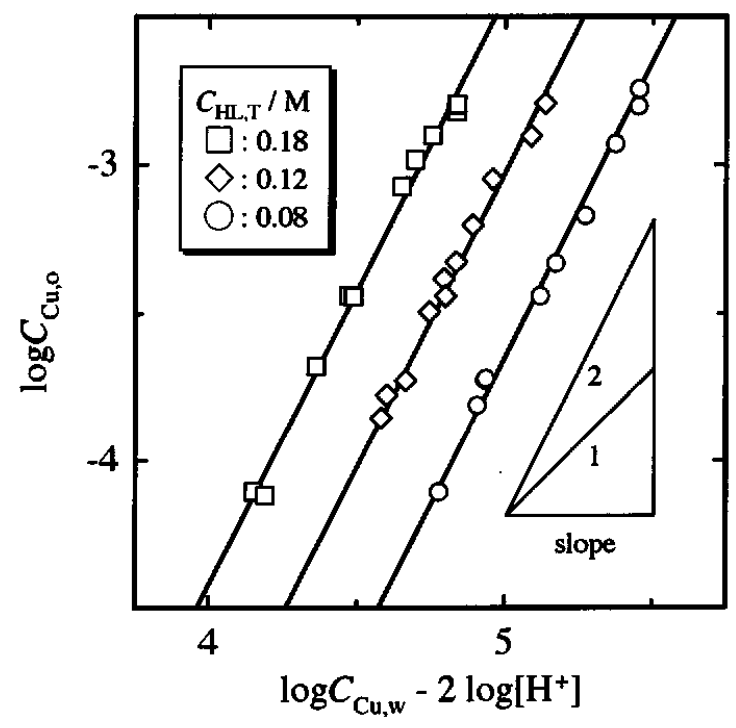

Fig. 6 Determination of the degree of oligomerization for copper(II) diphenylacetate in benzene. Solid lines are calculated from the results obtained in this work.

The plots of $\log C_{\mathrm{Cu}, \mathrm{o}} v s . \log C_{\mathrm{Cu}, \mathrm{w}}-2 \log \left[\mathrm{H}^{+}\right]$are shown in Fig. 6. A linear relation with a slope of 2.0 is observed for each $C_{\mathrm{HL}, \mathrm{T}}$ measurement. The results show that the extracted species could only be a dimer in the concentration range $-4.2<\log C_{\mathrm{Cu}, 0}<-2.7$. The linear plots of $\log C_{\mathrm{Cu}, \mathrm{o}}-2\left\{\log C_{\mathrm{Cu}, \mathrm{w}}-2 \log \left[\mathrm{H}^{+}\right]\right\}$vs. $\log \left(C_{\mathrm{HL}, \mathrm{T}} / 2\right)$, however, yield a slope of $c a .3 .5$ which produced an impossible composition of $\mathrm{Cu}_{2} \mathrm{~L}_{4}(\mathrm{HL})_{3}$, which seems to be caused by the assumption, $\left[(\mathrm{HL})_{2}\right]_{0}=C_{\mathrm{HL}, \mathrm{T}} / 2$ adopted due to lack of a value for $K_{2, \mathrm{HL}}$, in spite of the low $C_{\mathrm{HL}, \mathrm{T}}$. According to the literature ${ }^{2}$, we can suppose that the 
Table 1 Several equilibrium constants

\begin{tabular}{clcccc}
\hline \multicolumn{1}{c}{ Acid } & $\mathrm{p} K_{\mathrm{a}}$ & $\log K_{\mathrm{D}, \mathrm{HL}}$ & $\log K_{2, \mathrm{HL}}$ & $\log K_{\operatorname{ex}(22)}$ \\
\hline 1. & Pivalic & 4.86 & -0.03 & 2.32 & -11.70 \\
2. & 2-Ethylbutyric & 4.54 & 0.08 & 2.75 & -10.99 \\
3. & Diphenylacetic & 3.64 & - & 1.67 & -9.25 \\
4. & 1-Adamantanecarboxylic & 4.92 & - & - & $-11.45^{11}$ \\
5. & Decanoic $^{3}$ & 4.92 & 2.41 & 2.80 & -11.45 \\
6. & Phenylacetic $^{7}$ & 4.13 & 0.19 & 1.68 & -10.41 \\
7. & 2-Bromopentanoic & & & & -7.87 \\
\hline
\end{tabular}

dimeric copper(II) carboxylate extracted into nonpolar solvents ought to be $\mathrm{Cu}_{2} \mathrm{~L}_{4}(\mathrm{HL})_{2}$. Therefore, both constants $K_{\mathrm{ex}(22)}$ and $K_{2, \mathrm{HL}}$ must be calculated by using a fixed composition and all the extraction data in Fig. 6 through out the following procedure.

If the composition, $\mathrm{Cu}_{2} \mathrm{~L}_{4}(\mathrm{HL})_{2}$ is reasonable as the only extracted species, Eq. (14) must be valid when $\left[(\mathrm{HL})_{2}\right]_{0}$ is known under the assumption, $\alpha_{\mathrm{Cu}}=1$. Since the aqueous [HL] is negligible under our experimental conditions, the concentration of free carboxylic acid in the organic phase can be written as:

$$
\begin{aligned}
C_{\mathrm{HL}, \mathrm{o}}^{\mathrm{f}} & =C_{\mathrm{HL}, \mathrm{T}}-6\left[\mathrm{Cu}_{2} \mathrm{~L}_{4}(\mathrm{HL})_{2}\right]_{\mathrm{o}} \\
& =C_{\mathrm{HL}, \mathrm{T}}-3 C_{\mathrm{Cu}, \mathrm{o}}=2\left[(\mathrm{HL})_{2}\right]_{\mathrm{o}}+[\mathrm{HL}]_{\mathrm{o}},
\end{aligned}
$$

where $[\mathrm{HL}]_{\mathrm{o}}$ can be obtained by using $K_{2, \mathrm{HL}}=\left[(\mathrm{HL})_{2}\right]_{\mathrm{o}} /$ $[\mathrm{HL}]_{0}^{2}$ from the following equation:

$$
2 K_{2, \mathrm{HL}}[\mathrm{HL}]_{\mathrm{o}}{ }^{2}+[\mathrm{HL}]_{\mathrm{o}}-C_{\mathrm{HL}, \mathrm{o}}^{\mathrm{f}}=0 .
$$

Then, $\left[(\mathrm{HL})_{2}\right]_{\mathrm{o}}$ in Eq. (14) under $\alpha_{\mathrm{Cu}}=1$ can be written as follows:

$$
\begin{aligned}
& {\left[(\mathrm{HL})_{2}\right]_{\mathrm{o}}=\left(C_{\mathrm{HL}, \mathrm{o}}^{\mathrm{f}}-[\mathrm{HL}]_{\mathrm{o}}\right) / 2} \\
& \quad=0.5\left[C_{\mathrm{HL}, \mathrm{o}}^{\mathrm{f}}+\left\{1-\left(1+8 K_{2, \mathrm{HL}} C_{\mathrm{HL}, \mathrm{o}}^{\mathrm{f}}\right)^{1 / 2}\right\} /\left(4 K_{2, \mathrm{HL}}\right)\right] .
\end{aligned}
$$

When variables $Y_{i}, X_{i}$ and parameters $p_{1}, p_{2}$ are defined as

$$
\begin{aligned}
& Y_{i}=\log C_{\mathrm{Cu}, \mathrm{o}}-2\left(\log C_{\mathrm{Cu}, \mathrm{w}}-2 \log \left[\mathrm{H}^{+}\right]\right), \quad X_{i}=C_{\mathrm{HL}, \mathrm{o}}^{\mathrm{f}} \\
& p_{1}=K_{2, \mathrm{HL}}, \quad p_{2}=\log \left(2 K_{\mathrm{ex}(22)}\right),
\end{aligned}
$$

a residual function $f_{i}$ for the difference of both sides of Eq. (14) is written as the following equation:

$$
f_{i}=Y_{i}-3 \log \left[0.5\left\{X_{i}+\frac{1-\left(1+8 p_{1} X_{i}\right)^{1 / 2}}{4 p_{1}}\right\}\right]-p_{2}
$$

Then, we can obtain the optimum values of $p_{1}$ and $p_{2}$ in Eq. (19) at the minimum sum of squares, $\sum_{i} f_{i}{ }^{2}$, by means of a nonlinear least squares method (Marquardt method). The values of $K_{2, \mathrm{HL}}$ for diphenylacetic acid and of $\log \left(2 K_{\operatorname{ex}(22)}\right)$ for dimeric copper(II) diphenylacetate were calculated to be 47.3 and -8.95 , which give $\log K_{2, \mathrm{HL}}=1.67$ and $\log K_{\mathrm{ex}(22)}=-9.25$, respectively. By using the value of $K_{2, \mathrm{HL}}=47.3$, the plots of $\log C_{\mathrm{Cu}, \mathrm{o}}-3 \log \left[(\mathrm{HL})_{2}\right]_{\mathrm{o}}$ vs. $2\left\{\log C_{\mathrm{Cu}, \mathrm{w}}-2 \log \left[\mathrm{H}^{+}\right]\right\}$produced a linear relationship with a slope of $1.0(r=0.998)$.

\section{Correlation between $\log K_{\operatorname{ex}(22)}$ and $\log K_{a}$}

Consequently, the extraction equilibria and the extraction constants for the three copper(II) carboxylates which are studied in this work are represented in the same equation as:

$$
\begin{aligned}
& 2 \mathrm{Cu}^{2+}+3(\mathrm{HL})_{2,0} \rightleftarrows\left(\mathrm{Cu}_{2} \mathrm{~L}_{4}(\mathrm{HL})_{2}\right)_{\mathrm{o}}+4 \mathrm{H}^{+} \\
& K_{\mathrm{ex}(22)}=\left[\mathrm{Cu}_{2} \mathrm{~L}_{4}(\mathrm{HL})_{2}\right]_{0}\left[\mathrm{H}^{+}\right]^{4}\left[\mathrm{Cu}^{2+}\right]^{-2}\left[(\mathrm{HL})_{2}\right]_{0}{ }^{-3}
\end{aligned}
$$

in the concentration range, $C_{\mathrm{Cu}, \mathrm{o}}>3 \mu \mathrm{M}$. The values are summarized in Table 1 together with other constants reported in the literature. ${ }^{3,7,11,14}$ The values of $\log K_{\operatorname{ex}(22)}$ decrease in the following order:

2-bromopentanoic $>$ diphenylacetic $>$ phenylacetic $>2$ ethylbutyric $>$ decanoic $=1$-adamantanecarboxylic $>$ pivalic acid.

The dissociation constants of the acids decrease in the same order. The plots of $\log K_{\mathrm{ex}(22)} v s . \log K_{\mathrm{a}}$ are shown in Fig. 7 with a solid line that shows the equation:

$$
\log K_{\operatorname{ex}(22)}=1.7 \log K_{\mathrm{a}}-3.2 \text {, }
$$

which has already been proposed by Fujii et al. ${ }^{14}$ They have obtained the equation by connecting the values $\left(\log K_{\mathrm{a}}, \log K_{\mathrm{ex}(22)}\right)$ for aliphatic carboxylic acid and for 2 bromopentanoic acid. The plots of our experimental data (No. 1-4, open circles) also fit well with the straight line shown in Fig. 7 including other data (open squares). According to the results obtained in this work, we conclude that the introduction of the more bulky substituent at the $\alpha$-position in carboxylic acid does not interfere with the dimerization of copper(II) carboxylates significantly.

Thus, we can suppose that (1) the effect of the steric hindrance caused by substituents at the $\alpha$-position in the acids on the dimerization of copper(II) carboxylate is not so significant, that (2) the extraction constant for most of 


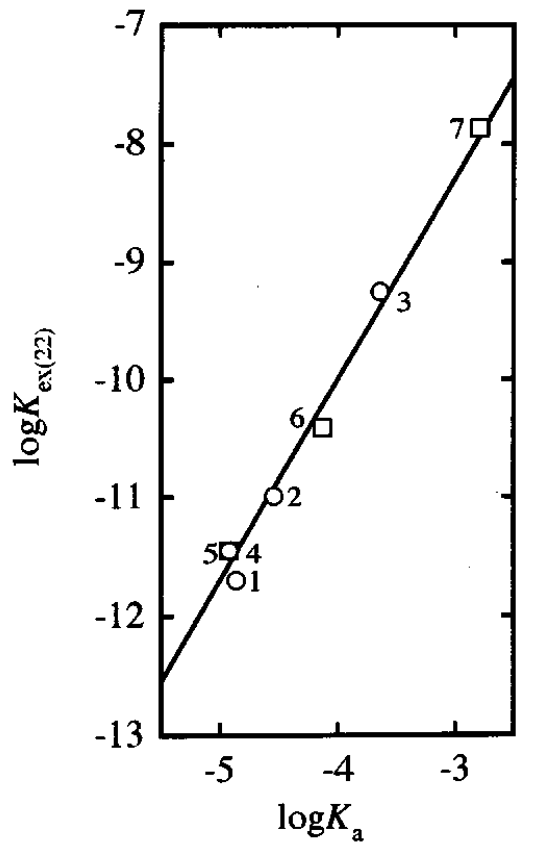

Fig. 7 Relation between the extraction constant of dimeric copper(II) carboxylate and the aqueous dissociation constant of the corresponding acid. The numbers in the figure are the same as those in Table 1. Solid line represents the equation: $\log K_{\mathrm{ex}(22)}=1.7 \log K_{\mathrm{a}}-3.2 .{ }^{14}$

the dimeric copper(II) complexes in benzene can be predicted by Eq. (22) except for carboxylates such as benzoate $^{8}$ and 1-naphthalenecarboxylate ${ }^{9}$, and that (3) the phenomenon of the coextraction of a monomeric copper(II) carboxylate accompanied with a dimeric copper(II) carboxylate comes about from a factor different from that of (1). Therefore, we will continue to investigate on this area in the near future.

\section{References}

1. Y. Moriya, M. Sugai, Y. Ohshima, N. Ogawa and M. Matsuo, Bunseki Kagaku, 43, 1137 (1994) and references therein.

2. H. Yamada and M. Tanaka, Adv. Inorg. Chem. Radiochem., 29, 143 (1985).

3. Y. Fujii, N. Nakasuka, M. Tanaka, H. Yamada and M. Mizuta, Inorg. Chem., 28, 3600 (1989).

4. W. J. Haffenden and G. J. Lawson, J. Inorg. Nucl. Chem., 29, 1333 (1970).

5. H. Yamada, M. Itoh and M. Mizuta, Bull. Chem. Soc. Jpn., 60, 3557 (1987).

6. H. Yamada and C. Kato, Talanta, 40, 1049 (1993).

7. H. Yamada, Y. Taguchi and H. Wada, Talanta, 41, 573 (1994).

8. H. Yamada, K. Yajima and H. Wada, Anal. Sci., 11, 715 (1995).

9. H. Yamada, Y. Matsui, Y. Kuroki and H. Wada, Anal. Sci., 13, 715 (1997).

10. Y. Baba and K. Inoue, Hydrometallurgy, 21, 203 (1988).

11. Y. Moriya, M. Sugai, Y. Ohshima and N. Ogawa, Anal. Sci., 12, 511 (1996).

12. I. Kojima, M. Yoshida and M. Tanaka, J. Inorg. Nucl Chem., 32, 986 (1970).

13. J. W. Bunting and K. M. Thong, Can. J. Chem., 48, 1654 (1970).

14. Y. Fujii, H. Yamada and M. Mizuta, Polyhedron, 6, 1203 (1987).

(Received August 6, 1997)

(Accepted September 4, 1997) 